\title{
Earnings And Job Satisfaction Of US Science And Engineering Baccalaureate Recipients With Advanced Degrees
}

\author{
R. Kim Craft, Southern Utah University, USA \\ Joe G. Baker, Southern Utah University, USA \\ Michael G. Finn, Oak Ridge Institute for Science and Education, USA
}

\begin{abstract}
Using 2003 US data, this paper examines job satisfaction and economic returns to science and engineering (STEM) baccalaureate recipients who obtain STEM PhDs or professional degrees in the fields of law, MBA, medicine, and MS engineering. The salient finding of this research is that the future STEM PhD supply will largely be determined by the availability of tenured academic positions. Despite inferior economic returns, job satisfaction for STEM PhD recipients significantly exceeds that of other professional degree recipients except for medicine. Superior job satisfaction for STEM PhDs results almost entirely from employment in tenured academic positions. 55 percent of STEM PhDs working outside the academic sector have similar job satisfaction compared to professional degree recipients but without the economic rewards. This analysis further suggests STEM PhDs would not have higher job satisfaction if they had completed degrees in medicine or law instead of PhDs. The policy to increase STEM PhD employment in the US economy has focused on supply. The findings of this paper indicate that a demand-side focus may be a more effective policy and that the future STEM PhD supply will be largely driven by the availability of fulltime tenure-track academic job openings.
\end{abstract}

Keywords: STEM; Science and Engineering Supply; Doctorates; Science And Engineering Baccalaureates

\section{INTRODUCTION AND STATEMENT OF THE PROBLEM}

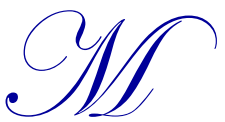

any in science policy have worried about the perceived insufficiency in the number of persons pursuing advanced degrees in science and engineering. ${ }^{1}$ Our interest in this topic was stimulated by the writings of Teitlebaum $(2001,2003)$ who, like some others (Butz et al. 2002), has questioned the proposition that there is a shortage in these fields. Indeed, recent data from the National Science Foundation (Fiegener 2015) indicates 2013 saw the highest number of research doctoral degrees awarded in the history of the Survey of Earned Doctorates at 52,760.

Teitlebaum argued that the conventional solution proposed to alleviate the alleged shortage is "profoundly misdirected" by focusing on supply rather than demand. He reasoned that a larger number of our brightest students would pursue graduate study in science and engineering if careers in these fields were more attractive relative to alternative careers, noting that professional training generally offers higher earnings with a shorter degree-completion time. Teitlebaum also recognized that income is not the only motivator and that careers in science and engineering have non-economic rewards that are appealing to some. However, neither Teitlebaum nor anyone else has systematically measured and compared these non-economic rewards relative to alternatives after controlling for undergraduate degree field.

The purpose of this study is to compare the relative career attractiveness of advanced degree recipients in the following advanced degree fields: medicine, law, MBA, MS engineering, and doctorates in science and engineering. Using 2003 US cross-sectional data, we compare degree fields using pecuniary and non-pecuniary (job satisfaction) criteria. Our

${ }^{1}$ See for example Rothwell 2014, National Research Council 2007 and Business Roundtable 2008. 
primary objective is to determine the validity of Teitlebaum's analysis. A unique aspect of this study is that the population examined is restricted to persons who earned baccalaureate degrees in natural science or engineering (STEM) fields. ${ }^{2}$ The authors were unable to find literature that addressed job satisfaction for STEM baccalaureates who received advanced degrees in STEM or professional fields.

\section{PREVIOUS RESEARCH}

The existing body of research on job satisfaction has produced some consistent findings. ${ }^{3}$ Job satisfaction is inversely correlated with quit rates and absenteeism (for example Clark \& Oswald 1996). Age and job satisfaction are related quadratically; i.e., job satisfaction tends to be highest for younger and older workers, and job satisfaction decreases as average weekly work hours increase (for example Vila \& Garcia-Mora 2005). Non-union workers and less-educated workers have higher job satisfaction (for example Belfield \& Harris 2002). Female job satisfaction exceeds males (for example Sousa-Poza \& Sousa-Poza 2000). The evidence regarding job satisfaction and race is very inconsistent, although most studies find insignificant effects after statistical controls (Clark \& Oswald 1996). A somewhat surprising finding is a lack of strong association between pay and job satisfaction, although evidence suggests that being "overpaid" compared to expectations, and not absolute income, produces satisfaction (for example Groot \& van den Brink 1999).

The literature on job satisfaction for holders of doctoral degrees is meager. Using the 1997 Survey of Doctorate Recipients, Moguerou (2001) examined a number of job satisfaction determinants for all PhD fields and obtained some notable results: female PhDs had lower job satisfaction than their male counterparts, and the earnings of PhDs had a clearly positive effect on job satisfaction. Sloane and Ward (2001) studied academics at five Scottish universities and found salary impacts job satisfaction mostly in a subjective way; that is, salary had an important effect when measured relative to what individuals felt they deserved. Sabharwal and Corley (2009) examined gender and disciplinary differences in faculty job satisfaction using the 2003 Survey of Doctorate Recipients and found female faculty had either the same or higher levels of satisfaction when appropriate control variables were included in the analysis.

Bender and Heywood $(2006,2011)$ published two papers examining job satisfaction of STEM PhDs. Their 2006 paper found higher job satisfaction in the academic sector was explained by tenure, and non-tenured academics were no more satisfied than PhDs in the government and private sector. Their 2011 paper examined the effect of educational mismatch (worker education not well matched with job requirements) and found that mismatch and lower job satisfaction occurred more frequently late in one's career.

Space does not permit a review of all the studies of job satisfaction of attorneys, physicians, and other health professionals; however, a study of income and job satisfaction among law graduates of the University of Michigan is noteworthy. Dau-Schmidt and Mukhopadhaya (1999) found that law graduates working in education reported the highest levels of job satisfaction, even though their earnings were below the average of other law graduates.

\section{METHOD AND DATA}

The objective of this paper is to compare recipients of advanced degrees using the following criteria: pecuniary returns (salary and internal rates of return to education) and non-pecuniary returns (job satisfaction). We begin with a tabular view of the differences in pecuniary and non-pecuniary returns to STEM baccalaureates who received advanced degrees in various fields. The analysis is extended with a multivariate regression model examining the factors affecting job satisfaction. Finally, we use the Oxaca decomposition technique to compare job satisfaction effects for STEM PhDs in job settings typical of professional fields.

The data for this analysis are from the 2003 National Survey of College Graduates (NSCG), a post-census stratified sample of all respondents in the US 2000 census who indicated they had a college degree. These data have several

\footnotetext{
${ }^{2}$ These include mathematics and computer science, life sciences, physical sciences and engineering. Excluded are social sciences and psychology.

${ }^{3}$ For an excellent review of job satisfaction literature see Bender, Donohue, \& Heywood (2005). 
attributes useful for this analysis, including extensive demographic information, educational attainment, work and earnings, and different measures of job satisfaction.

The sample was restricted to individuals who received a bachelor's degree in one of the following areas: life sciences, physical sciences, mathematics and computer science, and engineering. This restriction at least partially controls for differences in preferences associated with undergraduate degree field. Also, it allows for a more accurate comparison of earnings differences between STEM PhDs and the professional fields. ${ }^{4}$ Because our population of interest is potential members of the STEM PhD workforce in the US, the sample was further confined to full-time employed workers who received a STEM baccalaureate degree from a US university. These restrictions resulted in a total sample of 6,810 records that, when weighted, yields 1,543,242 workers (except where noted, all statistics reported in this paper are weighted).

\section{Pecuniary Rewards}

Table 1 presents employment and median earnings by advanced degree field and sector of employment. These data indicate STEM PhDs are concentrated in the education sector (45 percent of all STEM PhDs) - the lowest paying sector for all degrees.

Within both the education and government sectors, STEM PhD earnings exceed those of other fields except medicine; in the business sector, STEM PhD earnings exceed those of other fields except medicine and law. This suggests employment sector explains much of the earnings advantage of professional degrees over STEM PhDs.

Table 1. 2003 Employment and 2002 Median Annual Earnings by Advanced Degree Field and Employment Sector

\begin{tabular}{|c|c|c|c|c|c|}
\hline \multirow{2}{*}{ Degree Field } & & \multicolumn{4}{|c|}{ Employment Sector } \\
\hline & & Academic & Government & Business & Total \\
\hline \multirow{3}{*}{ STEM PhD } & \multirow{2}{*}{ Number Employed } & 129,952 & 36,039 & 124,771 & 290,762 \\
\hline & & $45 \%$ & $12 \%$ & $43 \%$ & $100 \%$ \\
\hline & Median Earnings & $\$ 70,000$ & $\$ 85,000$ & $\$ 97,000$ & $\$ 83,000$ \\
\hline \multirow{3}{*}{ Medical Degree } & \multirow{2}{*}{ Number Employed } & 88,135 & 20,367 & 366,813 & 475,316 \\
\hline & & $19 \%$ & $4 \%$ & $77 \%$ & $100 \%$ \\
\hline & Median Earnings & $\$ 80,000$ & $\$ 100,000$ & $\$ 144,000$ & $\$ 130,000$ \\
\hline \multirow{3}{*}{ Law Degree } & \multirow{2}{*}{ Number Employed } & 1,192 & 13,240 & 52,733 & 67,165 \\
\hline & & $2 \%$ & $20 \%$ & $79 \%$ & $100 \%$ \\
\hline & Median Earnings & N/A & $\$ 82,000$ & $\$ 105,000$ & $\$ 100,000$ \\
\hline \multirow{3}{*}{ MBA } & \multirow{2}{*}{ Number Employed } & 18,820 & 31,387 & 324,757 & 374,965 \\
\hline & & $5 \%$ & $8 \%$ & $87 \%$ & $100 \%$ \\
\hline & Median Earnings & $\$ 50,000$ & $\$ 79,000$ & $\$ 93,000$ & $\$ 90,000$ \\
\hline \multirow{3}{*}{ Engineering MS } & \multirow{2}{*}{ Number Employed } & 16,335 & 46,514 & 272,186 & 335,034 \\
\hline & & $5 \%$ & $14 \%$ & $81 \%$ & $100 \%$ \\
\hline & Median Earnings & $\$ 53,000$ & $\$ 76,000$ & $\$ 88,000$ & $\$ 85,000$ \\
\hline \multirow{3}{*}{$\begin{array}{l}\text { STEM BS/BA, } \\
\text { Highest Degree }\end{array}$} & \multirow{2}{*}{ Number Employed } & 282,231 & 404,191 & $2,490,648$ & $3,177,070$ \\
\hline & & $9 \%$ & $13 \%$ & $78 \%$ & $100 \%$ \\
\hline & Median Earnings & $\$ 40,000$ & $\$ 59,000$ & $\$ 70,000$ & $\$ 65,000$ \\
\hline
\end{tabular}

Information represents full-time workers with STEM Bachelors degrees earned in the US. Source: 2003 NSCG.

Earnings data only capture benefits and not costs associated with obtaining advanced degrees. Table 2 presents estimates of lifetime training costs, net benefits, and internal rates-of-return associated with the degree fields of interest. Because the population under consideration all possess high-paying STEM baccalaureates, a major cost is foregone earnings while in graduate or professional school. Thus, the extensive training period for the STEM PhD makes it an inferior economic investment compared to other degree fields.

\footnotetext{
${ }^{4}$ Descriptive data show significantly higher earnings for professionals who have STEM baccalaureates than non-STEM baccalaureates. 
Table 2. Training Costs, Benefits and Internal Rates of Return by Advanced Degree Field

\begin{tabular}{|c|c|c|c|c|c|}
\hline & STEM PhD & $\begin{array}{l}\text { Medical } \\
\text { Degree }\end{array}$ & Law Degree & MBA & Engineering MS \\
\hline \multicolumn{6}{|l|}{ Training Costs } \\
\hline $\begin{array}{l}\text { Annual direct costs } \\
\text { (e.g., books, tuition) }\end{array}$ & $-\$ 15,900^{a}$ & $\$ 25,800$ & $\$ 25,500$ & $\$ 20,200$ & $\$ 20,200$ \\
\hline $\begin{array}{l}\text { Annual opportunity cost } \\
\text { of foregone earnings } b\end{array}$ & $\$ 47,800$ & $\$ 43,700$ & $\$ 42,200$ & $\$ 40,800$ & $\$ 40,800$ \\
\hline Total annual costs ${ }^{\mathrm{b}}$ & $\$ 32,800$ & $\$ 69,500$ & $\$ 67,700$ & $\$ 61,000$ & $\$ 61,000$ \\
\hline Training period (years) & 7 & 4 & 3 & 2 & 2 \\
\hline $\begin{array}{l}\text { Total opportunity cost } \\
\text { of residency (4 years) }\end{array}$ & -- & $\$ 37,600$ & -- & -- & -- \\
\hline Total training costs & $\$ 229,600$ & $\$ 315,600$ & $\$ 203,100$ & $\$ 122,000$ & $\$ 122,000$ \\
\hline \multicolumn{6}{|l|}{ Benefits } \\
\hline Total lifetime earnings & $\$ 2,760,700$ & $\$ 4,690,000$ & $\$ 3,963,800$ & $\$ 3,217,400$ & $\$ 3,369,200$ \\
\hline $\begin{array}{l}\text { Total lifetime STEM } \\
\text { baccalaureate earnings }\end{array}$ & $\$ 2,317,300$ & $\$ 2,467,900$ & $\$ 2,525,000$ & $\$ 2,570,200$ & $\$ 2,570,200$ \\
\hline Net benefits to training & $\$ 443,400$ & $\$ 2,222,100$ & $\$ 1,438,800$ & $\$ 647,200$ & $\$ 799,000$ \\
\hline Internal Rate of Return & $2.5 \%$ & $10.0 \%$ & $10.7 \%$ & $14.5 \%$ & $15.6 \%$ \\
\hline \multicolumn{6}{|c|}{$\begin{array}{l}\text { a STEM PhD graduate programs are assumed to provide support for students sufficient to generate } \$ 15,000 \text { in net income in } \\
\text { year one and increasing at a real rate of } 2 \text { percent per year, hence negative direct training costs. } \\
\text { b Costs and foregone earnings are assumed to increase during training; these are annual averages for exposition. } \\
\text { c Medical residency is considered a training cost. This is estimated as the difference between median baccalaureate earnings } \\
\text { and residency earnings. }\end{array}$} \\
\hline
\end{tabular}

These estimates are based upon median earnings by age for the degree fields of interest and for baccalaureate STEM recipients. For example, the 2003 NSCG data indicate baccalaureate STEM degree recipients had median earnings of $\$ 39,200$ in their first year, increasing to $\$ 55,700$ in year seven. Averaging these median earnings by year produces $\$ 47,800$ per year lost for seven years while a student is pursuing a STEM PhD. Assuming a 40 -year horizon to retirement from receipt of baccalaureate, the $\mathrm{PhD}$ will have a 33-year window to accrue benefits to this 7-year training period. During those 33 years a STEM baccalaureate would have earned a total of $\$ 2,317,300$; the $\mathrm{PhD}$ earnings are $\$ 2,760,700$ for net economic benefits of $\$ 443,400$. Calculating the internal rate-of-return (IRR) produces an estimate of 2.5 percent for the STEM PhD. This low IRR is comparable to a government bond. All other degree fields produce far superior IRRs. The MBA and engineering MS have an IRR exceeding 14 percent, primarily due to relatively low training costs.

Some sensitivity analysis was performed with these models. Because the majority of training costs are generated through foregone earnings, changing direct costs had only small effects on the IRR. Extending the working life to 45 years likewise had very small effects on the IRR. The model assumes that time-to-degree for the $\mathrm{PhD}$ is seven years; lengthy time-to-degree is seen by some as a major deterrent to increasing the PhD supply. Reducing time-to-degree to six years would reduce training costs from $\$ 229,600$ to $\$ 184,100$ and add one year of earnings increasing the IRR for a STEM PhD from 2.5 to 3.6 percent. While this is a substantial improvement, the IRR for a STEM PhD still lags considerably behind the other degree fields.

\section{Non-Pecuniary Rewards}

The NSCG asked respondents to rank 10 job satisfaction characteristics using a four item Likert scale of "very satisfied," "somewhat satisfied," "somewhat dissatisfied," and "very dissatisfied." Table 3 contains the ratio very satisfied with their job by advanced degree and employment sector. Overall, the ratio of STEM PhDs who are very satisfied with their jobs is .558, which exceeds all other degree fields except professionals with medical degrees. The difference in job satisfaction between STEM PhDs and law degree recipients is statistically insignificant. Medical professionals attain substantially higher rates of job satisfaction compared to other careers by a wide margin. The exception is the government sector where no significant difference exists between STEM PhD's and medical degree recipients' job satisfaction. 
Table 3. Ratio Very Satisfied by Advanced Degree and Employment Sector

\begin{tabular}{l|c|c|c|c}
\hline \multicolumn{1}{c}{ Degree } & \multicolumn{3}{c}{ Employment Sector } & Total \\
\hline STEM PhD & Academic & Government & Business & 0.558 \\
\hline Medical Degree & 0.591 & 0.616 & 0.506 & $\underline{\mathbf{0 . 6 8 9}}$ \\
\hline Law Degree & $\mathbf{0 . 7 1 3}$ & 0.624 & $\underline{\mathbf{0 . 6 8 6}}$ & 0.507 \\
\hline MBA & 0.609 & 0.518 & $\mathbf{0 . 4 1 4}$ & $\underline{\mathbf{0 . 4 3 5}}$ \\
\hline Engineering MS & 0.631 & 0.533 & 0.436 & $\underline{\mathbf{0 . 4 4 9}}$ \\
\hline STEM BS/BA, Highest Degree & 0.539 & 0.496 & $\mathbf{0 . 4 2 5}$ & $\underline{\mathbf{0 . 4 3 7}}$ \\
\hline All Fields & $\underline{\mathbf{0 . 4 7 4}}$ & 0.483 & 0.455 & 0.471 \\
\hline
\end{tabular}

ANOVA significance between STEM PhD and other degrees: $10 \%, 5 \%, \underline{\mathbf{1 0}}$.

Source: 2003 NSCG.

When one disaggregates by employment sector, most significant differences between degree fields vanish. This implies that the superior job satisfaction of STEM PhDs is partially driven by sector of employment. Academic and government workers have relatively higher rates of job satisfaction than business workers and, as shown in Table 1, approximately two out of three STEM PhDs are employed in these sectors.

Table 4 contains job satisfaction information regarding various job attributes by degree field. The NSCG queried each respondent as to the level of satisfaction with 9 separate job characteristics (e.g., "Thinking about your principal job, please rate your satisfaction with that job's salary"). For example, 70.8 percent of STEM PhD recipients indicated they were very satisfied with the degree of independence of their jobs; only 32.1 percent indicated they were very satisfied with the advancement opportunities of their job.

Table 4. Ratio Very Satisfied by Job Attribute

\begin{tabular}{|c|c|c|c|c|c|c|}
\hline \multirow[b]{2}{*}{ Job Attribute } & \multicolumn{6}{|c|}{ Degree } \\
\hline & $\begin{array}{c}\text { STEM } \\
\text { PhD }\end{array}$ & $\begin{array}{c}\text { Medical } \\
\text { Degree }\end{array}$ & $\begin{array}{c}\text { Law } \\
\text { Degree }\end{array}$ & MBA & $\begin{array}{c}\text { Engineer } \\
\text { MS }\end{array}$ & $\begin{array}{l}\text { STEM } \\
\text { BS/BA }\end{array}$ \\
\hline Degree of independence & $.708(1)$ & $.717(4)$ & $.754(1)$ & $.613(1)$ & $.617(1)$ & $.629(1)$ \\
\hline Intellectual challenge & $.658(2)$ & $.788(3)$ & $.652(2)$ & $.426(4)$ & $.457(4)$ & $.432(4)$ \\
\hline Level of responsibility & $.610(3)$ & $.807(2)$ & $.634(3)$ & $.446(3)$ & $.470(3)$ & $.493(3)$ \\
\hline Job location & $.593(4)$ & $.643(6)$ & $.603(4)$ & $.547(2)$ & $.569(2)$ & $.588(2)$ \\
\hline Contribution to society & $.587(5)$ & $.857(1)$ & $.540(6)$ & $.340(8)$ & $.380(8)$ & $.404(6)$ \\
\hline Job security & $.489(6)$ & $.710(5)$ & $.600(5)$ & $.394(6)$ & $.415(6)$ & $.426(5)$ \\
\hline Benefits & $.465(7)$ & $.496(7)$ & $.370(9)$ & $.401(5)$ & $.417(5)$ & $.386(7)$ \\
\hline Salary & $.349(8)$ & $.434(9)$ & $.393(8)$ & $.371(7)$ & $.379(7)$ & $.330(8)$ \\
\hline Advancement opportunities & $.321(9)$ & $.484(8)$ & $.404(7)$ & $.284(9)$ & $.247(9)$ & $.254(9)$ \\
\hline Overall satisfaction & 0.558 & 0.689 & 0.507 & 0.435 & 0.449 & 0.437 \\
\hline
\end{tabular}

Ordinal ranking within degree in parentheses. Source: 2003 NSCG.

STEM PhDs have the highest job satisfaction with the degree of independence in their job, followed by intellectual challenge and level of responsibility. With the exception of medicine, workers with all degrees rank "degree of independence" as the job attribute that produces the most satisfaction; all workers tend to rank salary and advancement opportunities low. Medical professionals have higher job satisfaction than STEM PhDs in every dimension of their jobs, and they are most satisfied with their job's perceived contribution to society. This statistic exceeds any job satisfaction attribute in the other degree areas by a large margin (Engineering MS degree holders were least satisfied with opportunities for advancement; this is the smallest statistic in table 4). Salary satisfaction rates low for all degree recipients; it is interesting to note medical degree holders (the highest paid, see Table 1) are the least satisfied with their salaries. There is a remarkable similarity in the ordinal rankings for STEM PhDs and those with law degrees.

\section{Models of Overall Job Satisfaction}

Job satisfaction is related to the entire "bundle" of job attributes. Previous research has shown worker characteristics (e.g., gender, age, marital status) also have significant effects on how individuals rate their job satisfaction. We 
estimate logistic regression models to examine how these variables determine overall job satisfaction and to analyze differences between degree fields.

The dependent variable in these models is a binary variable equal to 1 if the worker reports very satisfied and equal to 0 if the worker reports any other level of job satisfaction (somewhat satisfied, somewhat dissatisfied, very dissatisfied). Ordered logit and probit models were also estimated using all four job satisfaction categories but we settled on a dichotomous-dependent variable specification because there were no important differences in the main conclusions, which is easily explained by the fact that about 93 percent of all STEM PhDs fell into either the very satisfied or somewhat satisfied category, and the results are easier to interpret.

Explanatory and control variables were chosen based upon data availablility and previous work on job satisfaction. Demographic variables included sex, race, age, disability status, marital and family status, and citizenship status. Employment variables included weekly hours, supervisor status, firm size, employment sector (government, academic, private), primary work activity (research, teaching, management, computer-related, other), and how closely workers perceived the relationship between their degree and job. Tenure status was included for persons in the academic sector. Education attainment variables included the five degrees: STEM PhD, medicine, law, MBA, and MS in engineering.

The effect of income on job satisfaction was captured in two ways. The variable "Insalary" is the natural log of earnings and captures the absolute effect of earnings on job satisfaction. Because previous research (e.g., Groot \& van den Brink 1999) has found that relative salary is an important determinate of job satisfaction, we also included a binary variable "overpaid" that indicates whether the worker had earnings greater than one would expect given worker and job characteristics. To calculate this variable, log-linear regression models were estimated for each degree field and used to estimate expected earnings. The log-linear model variables included employment sector, firm size, worker job type, worker demographic characteristics, hours, and region. The overpaid variable equals 1 when the worker's actual salary is greater than expected given observed worker and job characteristics, and zero otherwise.

Table 5 contains the estimated coefficients (in a few cases, variables were dropped when there were insufficient observations in the category). An unrestricted model was estimated combining data for all degree fields, with dummy variables to control for degree fields, and specifying STEM PhD as the excluded category. Restricted models were then estimated for each of the advanced degrees under consideration. The first two columns in Table 5 detail the estimation results of the unrestricted model for all advanced degree fields combined (All Fields) and for STEM PhDs. While results for the other degree areas are included in Table 5, the following discussion focuses on the models for All Fields and STEM PhD's because these are the areas of primary interest. All models were significant except the medical model. The salient finding is that once one controls for job and worker characteristics, the job satisfaction of STEM PhDs does not differ significantly from that of the other advanced degree recipients examined. 
Table 5. Logistic Regression Results

\begin{tabular}{|c|c|c|c|c|c|c|}
\hline \multirow[b]{2}{*}{ Variables } & \multicolumn{6}{|c|}{ Degree Field } \\
\hline & All Fields & STEM PhD & MD & Law & MBA & MS Engin. \\
\hline Female & 0.082 & 0.194 & -0.130 & 0.543 & 0.285 & 0.003 \\
\hline AsianNonHisp & $\underline{-0.496}$ & -0.227 & -0.209 & -1.480 & $\underline{-1.357}$ & -0.504 \\
\hline BlackNonHisp & $\overline{-0.321}$ & -0.273 & -0.299 & -2.015 & $\overline{0.033}$ & -0.713 \\
\hline OtherRaceNonHisp & -0.578 & -0.355 & -0.472 & -- & -0.407 & -0.779 \\
\hline Hispan & 0.024 & 0.131 & -0.418 & 0.756 & 0.130 & 0.324 \\
\hline CAREERAGE & -0.060 & $\underline{-0.083}$ & $\underline{-0.091}$ & -0.008 & -0.051 & -0.055 \\
\hline CAREERAGESQ & $\overline{0.002}$ & $\overline{0.002}$ & $\overline{0.003}$ & 0.001 & $\overline{0.002}$ & 0.002 \\
\hline PhyDisability & $\underline{-0.516}$ & $\overline{-0.819}$ & $-\overline{-0.921}$ & -1.580 & -0.848 & 0.267 \\
\hline Married & 0.343 & 0.192 & 0.468 & -0.045 & 0.653 & 0.403 \\
\hline Children & $\overline{0.048}$ & 0.044 & 0.013 & 0.272 & $\overline{0.140}$ & 0.068 \\
\hline NotUScitizen & 0.021 & -0.235 & 0.398 & 2.594 & 0.465 & -0.467 \\
\hline lnsalary & 0.232 & 0.189 & 0.251 & 0.398 & 0.366 & 0.110 \\
\hline overpaid & $\overline{0.197}$ & 0.357 & 0.282 & -0.625 & 0.117 & 0.249 \\
\hline lnhrswork & 0.002 & -0.148 & -0.113 & 0.472 & 0.120 & -0.026 \\
\hline Supervisor & $\underline{0.038}$ & 0.229 & -0.276 & 0.385 & 0.016 & 0.241 \\
\hline firmLT500 & $\overline{0.316}$ & 0.149 & 0.378 & -0.288 & 0.393 & 0.362 \\
\hline MEDICINE & $\overline{0.502}$ & -- & -- & -- & -- & -- \\
\hline LAW & -0.205 & -- & -- & -- & -- & -- \\
\hline MBA & -0.102 & -- & -- & -- & -- & -- \\
\hline MSENG & -0.140 & -- & -- & -- & -- & -- \\
\hline Gov & $\underline{0.458}$ & 0.530 & -0.121 & 0.170 & $\underline{0.812}$ & 0.341 \\
\hline Academic & $\overline{0.671}$ & 0.794 & 0.090 & -- & $\overline{1.464}$ & 0.246 \\
\hline tenuretrack & $\overline{0.398}$ & -0.078 & 1.098 & -- & 3.433 & -- \\
\hline jobnottenuretrack & -0.330 & -0.453 & 0.105 & -- & 0.181 & -2.061 \\
\hline tenurenotapplic & -0.154 & -0.608 & 0.328 & -- & -0.032 & 0.611 \\
\hline ActComp & -0.126 & 0.207 & -- & -- & 0.038 & -0.209 \\
\hline ActTeach & -0.367 & -0.321 & -1.689 & -- & -0.898 & 0.745 \\
\hline ActManage & -0.014 & -0.071 & $\overline{-0.699}$ & -- & 0.010 & 0.000 \\
\hline ActOther & -0.038 & -0.068 & -0.972 & 0.653 & -0.546 & 0.292 \\
\hline JobDegclose & 0.455 & -0.223 & -2.077 & 2.760 & 0.360 & 0.968 \\
\hline JobDegrelated & $-\overline{-0.096}$ & -0.428 & -1.726 & 1.613 & -0.382 & $\overline{0.368}$ \\
\hline Constant & -3.230 & -1.428 & 1.360 & -9.381 & -5.710 & -2.643 \\
\hline Observations & $\overline{6,810}$ & 1,734 & 1,440 & 148 & 1,392 & 2,066 \\
\hline Hosmer Lemeshow Test & 0.949 & 0.636 & 0.039 & 0.234 & 0.545 & 0.732 \\
\hline
\end{tabular}

Level of significance: $\mathbf{1 0} \%, \mathbf{5 \%}, \underline{\mathbf{1 \%}}$. Source: Estimated from 2003 NSCG data.

Some key results are as follows: Gender does not significantly affect satisfaction with one's job. Advanced degree recipients who were Asian, black, or other races, reported significantly less satisfaction than non-Hispanic whites (the excluded category). Race is an insignificant determinant of job satisfaction for STEM PhDs. Career age (years since degree) has the expected convex relationship, which significantly affects job satisfaction in all degree fields except law. Having a physical disability significantly reduced job satisfaction for the unrestricted model and in all individual degree areas except engineering. Advanced degree recipients who were married had significantly higher job satisfaction than unmarried for the unrestricted model, but this did not hold for STEM PhDs. Neither the presence of children nor US citizenship status significantly affects job satisfaction. The lnsalary coefficient indicates absolute earnings have a significant and positive effect on job satisfaction for the unrestricted model; however, the effect of earnings was insignificant for STEM PhDs. As expected, the variable overpaid is significant and positive in both models. Working as a supervisor did not significantly affect job satisfaction from other advanced degree workers except in the unrestricted and medical degree models (although the effects are opposite). Workers in small firms or institutions (variable firmLT500) indicate significantly higher satisfaction compared to firms of 500 or more employees for the total model, but not for STEM PhDs. 
The unrestricted model indicates the effect of degree field on job satisfaction. All of the advanced degree variables are statistically insignificant implying STEM PhDs (the excluded category) do not have significantly higher job satisfaction ceteris paribus. On the other hand, advanced-degree recipients who work in the government and academic sectors have significantly higher job satisfaction than those in the business sector (the excluded category). When combined with the descriptive data in Table 3 these results suggest that differences in job satisfaction between advanced-degree recipients are driven more by the sector of employment than the degree field. This finding is consistent with Teitlebaum's demand-side analysis.

To test this further, the unrestricted model described in Table 5 was reestimated with the employment-sector and tenure-related variables omitted. ${ }^{5}$ All of the degree field coefficients became significant at a 1 percent level except law, which was insignificant. The coefficient for medicine became significantly positive; the other degree field coefficients were negative. This finding is consistent with those of Bender and Heywood (2006) and Dau-Schmidt and Mukhopadhaya (1999). Bender and Heywood (2008) found that overall higher job satisfaction of STEM PhDs was explained by tenured academic positions which produce very satisfied workers. Dau-Schmidt and Mukhopadhaya found that law degree recipients working as professors had higher job satisfaction than law degree recipients working in other settings.

Three variables related to tenure (tenure track, not tenure track, and tenure not applicable) were included in the model to test for tenure effects on job satisfaction (tenure being the excluded category). None of these are significant in the unrestricted model; "tenure not applicable" is significant and negative in the STEM PhD model.

Five variables examining primary job activity were examined: primary activity computer-related, teaching, management, other, and research (the excluded category). These job activity variables had no significant effect on job satisfaction in the STEM PhD model. The NSCG survey queried workers regarding how closely their degree matched their work with three responses possible: closely related, somewhat related, or not related (excluded). In the total model, employees whose work is closely related to their degree had significantly higher job satisfaction than those who indicated job/degree were not related. In the STEM PhD model, job/degree mismatch produced no significant effects on job satisfaction.

\section{Estimating Job Satisfaction}

Comparing job satisfaction across degree fields is complicated by the fact that individuals self-select into degree fields based upon career preferences. For instance, the percentage of very satisfied professionals with a medical degree is 68.9 percent; the same statistic for STEM PhDs is 55.8 percent (Table 3). One cannot assume 68.9 percent of STEM PhDs would be very satisfied had they gone into medicine.

Would the job satisfaction of STEM PhDs increase or decrease if they switched jobs from a tenured academic position to become a practicing physician or a business manager? The STEM PhD model indicates how individual job characteristics (e.g, salary, weekly hours, primary work activity) affect job satisfaction for a STEM PhD. One approach to examining this question is to hold a worker's job satisfaction function (as estimated in Table 5) constant and vary the bundle of job attributes to match those found in other fields. ${ }^{6}$ This approach provides an estimate of the level of job satisfaction that would be obtained by a STEM PhD working in a job having the characteristics found in other fields. Using the preference functions from Table 5, we can decompose job satisfaction into differences in the characteristics of jobs and differences in the way these job characteristics determine job satisfaction. Table 6 shows the results of evaluating the STEM PhD equation from Table 5 at alternative sets of job characteristics.

The assumptions in the table are based upon representative characteristics for each of the job bundles estimated from the NSCG data. All demographic variables were fixed at the indicated levels. If a typical tenured, academic STEM PhD were to switch jobs with a physician there would be major changes in his or her job characteristics: a large

\footnotetext{
${ }^{5}$ Bender and Heywood (2006) found that most of the difference in job satisfaction between academic and nonacademic scientists was related to tenure.

${ }^{6}$ This technique was developed by economist Ron Oaxaca (1973) and is termed an "Oaxaca decomposition." Oaxaca used this technique to estimate gender wage gaps. As is statistical convention, the estimations reported here include all model variables regardless of significance.
} 
increase in income, the loss of tenure, a small increase in weekly hours, a change in work activity, and a change in firm size. When the STEM PhD job satisfaction equation is evaluated at the job attributes of an MD, the probability of a representative individual feeling very satisfied is only 28.1 percent, far below the 55.4 percent value predicted for a tenured, academic STEM PhD (Academic 1). The story is much the same when evaluating the STEM PhD equation at the job characteristics associated with the fields of law, MBA, and engineering MS-i.e., we observe large drops in the predicted probability that the representative worker would be very satisfied. ${ }^{7}$

Table 6. Predicted Job Satisfaction, Evaluating STEM PhD Equation under Alternative Scenarios

\begin{tabular}{|c|c|c|c|c|c|c|c|}
\hline \multirow[b]{2}{*}{ Job Bundle } & \multicolumn{6}{|c|}{ Job Bundle Asssumptions ${ }^{\text {a }}$} & \multirow{2}{*}{$\begin{array}{c}\text { Estimated } \\
\text { Probability of } \\
\text { being Very }^{\text {Satisfied }}\end{array}$} \\
\hline & Sector & Earnings & $\begin{array}{l}\text { Weekly } \\
\text { Hours }\end{array}$ & $\begin{array}{l}\text { Firm } \\
\text { Size }\end{array}$ & Job Activity & Tenure Status & \\
\hline Academic 1 & Ac & $\$ 77,395$ & 51.0 & $500+$ & Research & Tenure & $55.4 \%$ \\
\hline Academic 2 & Ac & $\$ 77,395$ & 51.0 & $500+$ & Research & Tenure Track & $53.5 \%$ \\
\hline Academic 3 & Ac & $\$ 77,395$ & 51.0 & $500+$ & Research & Not Tenure Track & $44.1 \%$ \\
\hline Government & Gov & $\$ 83,138$ & 46.2 & $500+$ & Research & $\mathrm{N} / \mathrm{A}$ & $34.8 \%$ \\
\hline Business & Bus & $\$ 109,665$ & 47.9 & $500+$ & Research & N/A & $24.9 \%$ \\
\hline Medicine & Bus & $\$ 187,542$ & 52.0 & $<500$ & Other & $\mathrm{N} / \mathrm{A}$ & $28.1 \%$ \\
\hline Law & Bus & $\$ 153,810$ & 51.4 & $<500$ & Other & N/A & $27.4 \%$ \\
\hline MBA & Bus & $\$ 125,197$ & 47.5 & $<500$ & Manage & $\mathrm{N} / \mathrm{A}$ & $31.4 \%$ \\
\hline MS Engineeer & Bus & $\$ 88,264$ & 47.9 & $<500$ & Research & $\mathrm{N} / \mathrm{A}$ & $26.8 \%$ \\
\hline MS Engineeer & Bus & $\$ 125,197$ & 45.6 & $<500$ & Manage & $\mathrm{N} / \mathrm{A}$ & $30.2 \%$ \\
\hline
\end{tabular}

The results shown in Table 6 clearly indicate why individuals choose to pursue a STEM PhD degree despite the relatively meager economic returns. Given the preferences of these individuals, the $\mathrm{PhD}$ allows access to jobs that produce large amounts of satisfaction. It is noteworthy how little earnings affect satisfaction for STEM PhDs. Earnings for law and medicine are over twice those of tenured STEM PhD academics and yet when we consider the entire bundle of job characteristics associated with these fields, the probability of a STEM PhD being very satisfied drops by about half.

The results also indicate academic research positions are the preferred jobs for STEM PhDs. The estimated probability of a person with STEM PhD job preferences being very satisfied in an academic research position ranges from 44.1 to 55.4 percent, depending on tenure status. The probability of the same person being very satisfied in the business sector doing research is only 24.9 percent, and it is similarly low for other sets of job characteristics: medicine, 28.1 percent; law, 27.4 percent; MBA, 31.4 percent; and Engineering, 26.8 to 30.2 percent. Finally, the simulations provide a strong illustration of the value of tenure. While academic STEM PhDs who have tenure (Academic 1) or are on a tenure track (Academic 2) have a relatively high probability of being very satisfied, the predicted value drops substantially for those who are not on tenure track (Academic 3).

\section{CONCLUSION}

The objective of this paper is to determine the validity of Teitlebaum's analysis and conclusion that future STEM PhD supply will be largely determined by the availability of attractive job openings. Our findings largely support this analysis. Tenured academic positions produce a high level of job satisfaction regardless of degree field and the STEM $\mathrm{PhD}$ provides greater access to these positions than the other advanced degrees considered. The job satisfaction of STEM PhDs working outside the academic sector is similar to that of other fields, without the superior economic rewards.

\footnotetext{
${ }^{7}$ Two types of job activities for MS engineers are included in the Table 6 simulations because there are a relatively large number of these persons working in both research (35 percent) and management (41 percent).
} 
What does this mean for those concerned about attracting more students to graduate programs in science and engineering? The inferior economic returns from investing in a STEM $\mathrm{PhD}$ degree compared with alternative professional degrees are well known, and have been cited as a deterrent to getting more college students to choose STEM careers. However, it turns out that earnings are not that important. The job satisfaction experienced by STEM baccalaureate recipients who obtain STEM PhDs is generally higher than the job satisfaction experienced by STEM baccalaureate recipients who obtain MS engineering, law or MBA degrees. While prospective STEM baccalaureate students considering a STEM doctoral program might still choose one of these alternatives primarily because the period of study is substantially shorter, this benefit must be weighed against a career of lower job satisfaction. In any case, our results indicate that economic returns are not the main factor involved in this choice.

Medicine is a different story. Medicine degree recipients are in the enviable position of having the highest median earnings as well as the highest levels of job satisfaction of any of the groups examined in this study. While the simulation reported in Table 6 can be used to make the case that the typical STEM PhD would experience lower levels of job satisfaction if he or she were to trade jobs with the typical MD, not everyone is "typical." There are those at the margin who may be undecided between an STEM PhD versus a medical program of study. Surely, the higher earnings and job satisfaction of medicine has influenced the choice for this group. However, statistics on degree awards by field of study (US Department of Education 2014) indicate that although there has been substantial growth in total professional degrees awarded in the past decade, the growth in MD degree awards has been modest. The simple explanation is that there are relatively more openings in STEM PhD programs than in medical schools.

In terms of job satisfaction, it is difficult to find a better career choice than a tenured academic position in science and engineering. As Teitlebaum suggested, the availability of these positions in the future will likely have a large effect on future STEM PhD degree production. Recent trends in higher education are troubling in this regard. Estimates by the authors using data from the Survey of Doctorate Recipients indicate the percentage of new STEM PhDs (doctorate awarded in last 10 years) who are tenured or on tenure track fell from 22.3 to 18.9 over the 10 year period from 2003 to 2013 , a 15 percent decline. It is likely that this decline is related to the growth in part-time and adjunct postions. If these demand-side trends continue, it will likely depress future STEM PhD production.

\section{ACKNOWLEDGEMENT}

The authors acknowledge funding from the Alfred P. Sloan Foundation supporting this research. The findings in this article are solely those of the authors.

\section{AUTHOR BIOGRAPHIES}

R. Kim Craft is professor of economics and chair of the Department of Economics and Finance at Southern Utah University in Cedar City, Utah.

Joe G. Baker is professor of managerial economics at Southern Utah University in Cedar City, Utah.

Michael G. Finn is senior research economist at the Oak Ridge Institute for Science and Education in Oak Ridge, Tennessee.

\section{REFERENCES}

Belfield, C.R. \& Harris, R.D.F. (2002). How well do theories of job matching explain variations in job satisfaction across educational levels? Evidence for UK graduates. Applied Economics, 34, 535-548.

Bender, K.A., Donohue, S.A., \& Heywood, J.S. (2005). Job satisfaction and gender segregation. Oxford Economic Papers, 57, 479-496.

Bender, K.A., \& Heywood, J.A. (2006). Job Satisfaction of the highly educated: The role of gender, academic tenure, and comparison income. Scottish Journal of Political Economy, 53, 253-279.

Bender, K.A., \& Heywood, J.A. (2011). Educational mismatch and the careers of scientists. Education Economics, 19, $253-274$.

Business Roundtable. (2008). U.S. technological and economic leadership at risk: Act now on U.S. competitiveness. Retrieved October 2009 from http://www.businessroundtable.org/node/3615. 
Butz, W.P., Bloom, G.A., Gross, M.E., Kelly, T.A., Kofner, A. \& Rippen, H.E. (2003). Is there a shortage of scientists and engineers? How would we know? Rand Corporation Science and Technology Issue Paper.

Clark, A.E. \& Oswald, A.J. (1996). Satisfaction and Comparison Income. Journal of Public Economics, 61, 359-381.

Dau-Schmidt, K. \& Mukhopadhaya, K. (1999). The fruits of our labors: An empirical study of the distribution of income and job satisfaction across the legal profession. Journal of Legal Education, 49(3)3, 342-366.

Fiegener, M.K. (2015). Doctorate recipients from U.S. universities. National Science Foundation, NSF 15-304.

Groot, W. \& Maassen van den Brink, H. (1999). Job satisfaction and preference drift. Economics Letters, 63, 363-367.

National Research Council, Committee on Prospering in the Global Economy of the 21st Century: An agenda for American science and technology, committee on science, engineering and public policy. National Academy of Sciences. (2007). Rising above the gathering storm: Energizing and employing America for a brighter economic future. Washington, D.C.: National Academy Press.

Moguerou, P. (2001). Job satisfaction among PhD Graduates: The effects of gender and employment sector. Paper given at the ZEW conference, Berlin Germany.

Oaxaca, R. (1973). Male-female wage differentials in urban labor markets. International Economic Review, 14, 693-709.

Rothwell, J. (2014). Still searching: Job vacancies and stem skills. Metropolitan Policy Program at Brookings. July 2014.

Sabharwal, M. \& Corley, E. (2009). Faculty job satisfaction across gender and discipline. The Social Science Journal, 46(3), 539-556.

Sloane, P.J., \& Ward, M.E. (2001). Cohort effects and job satisfaction of academics. Applied Economics Letters, 8, 787-791.

Sousa-Poza, A. \& Sousa-Poza, A.A. (2000). Taking another look at the gender/job satisfaction paradox. Kyklos, 53, $135-152$.

Teitelbaum, M.S. (2001). How we (unintentionally) make scientific careers unattractive. In Chubin, D.E. \& Person W.Jr. (eds.). Scientists and Engineers for the New Millennium: Renewing the Human Resource. Alfred P. Sloan Foundation.

Teitelbaum, M.S. (2003). Do we need more scientists? The Public Interest, 153, 40-53.

US Department of Education. (2014). Digest of education statistics 2014. US Department of Education National Center for Education Statistics.

Vila, L.E. \& Garcia-Mora, B. (2005). Education and the determinants of job satisfaction. Education Economics, 13(4), 409-25. 


\section{NOTES}

